\title{
GSAP: Güç Sistem Analizi Uygulaması için Matlab Tabanlı Grafik Paketi
}

\author{
Hakan ÇAKAR ${ }^{*}$, Muhsin Tunay GENÇOĞLU ${ }^{2}$ \\ ${ }^{1}$ Fırat Üniversitesi, Teknoloji Fakültesi, Elektrik-Elektronik Mühendisliği Bölümü, Elazığ, Türkiye \\ ${ }^{2}$ Fırat Üniversitesi, Mühendislik Fakültesi, Elektrik-Elektronik Mühendisliği Bölümü, Elazığ, Türkiye \\ ${ }^{* 1}$ hcakar@firat.edu.tr
}

Öz: Bu çalışmada, elektrik güç sistemlerinde kısa devre arızaları, iletim hatları hesaplamaları, kesici açma gücü hesabı ve yük akış analizi için kullanılabilecek, Matlab/Guide tabanlı GSAP (Güç Sistemleri Analiz Programı) isimli bir program geliştirilmiştir. Geliştirilen bu paket program, Matlab programının sunduğu nümerik ve görsel imkânlardan faydalanmaktadır. Matlab yazılımı; kolay erişilebilmesi ve sunduğu paket programların zenginliğinden dolayı güç sistemlerinin dinamik analizlerinde en çok tercih edilen araçlardan biridir. GSAP'da geliştirilen kullanıcı ara yüzleri; kısa devre arızaları, iletim hatları hesaplamaları, kesici açma gücü hesabı ve yük akış analizlerinin kolayca yapılabilmesini sağlamaktadır. GSAP'ın etkinliği, doğruluğu ve başlıca özellikleri bazı örnek güç sistemleri uygulamaları ile test edilmiştir. Geliştirilen simülatör kullanıcı etkileşimli olup, lisans ve yüksek lisans seviyesindeki güç sistemleri analizi derslerini desteklemek için kullanılabilmektedir. Anahtar kelimeler: Elektrik güç sistemleri, modelleme, analiz, eğitim, matlab.

GSAP: A Matlab-based Graphical Package for Implementing Power System Analysis

Abstract: In this study, a program called Matlab / Guide based GSAP (Power Systems Analysis Toolbox) has been developed which can be used for short circuit faults in electrical power systems, transmission line calculations, breaker opening power calculation and load flow analysis. This developed package program utilizes the numerical and visual possibilities offered by the Matlab program. Matlab software; it is one of the most preferred tools in the dynamic analysis of power systems due to its easy accessibility and richness of the package programs it offers. User interfaces developed in GSAP; short circuit faults, transmission line calculations, breaker opening power calculation and power flow analysis can be done easily. The effectiveness, accuracy and main features of GSAP have been tested with some sample power systems applications. The developed simulator is user interactive and can be used to support undergraduate and graduate level power systems analysis courses.

Key words: Electrical power systems, modeling, analysis, education, matlab.

\section{Giriş}

Güç sistemleri; enerji iletim ve dağıtım hatları, elektrik makineleri ve koruma elemanlarının oluşturduğu oldukça karmaşık sistemlerdir. Bu sistemler, elektrik enerjisinin üretimi, dağıtımı ve kullanımı aşamalarıyla birlikte bir bütün olarak ele alınmaktadır. Enterkonnekte yapıya sahip olan ve her geçen gün büyüyerek daha geniş coğrafi alanlara yayılan güç sistemlerinin planlama, işletme ve kontrol işlemlerinde bilgisayara dayalı çözüm tekniklerine başvurulması kaçınılmazdır [1]. Bu amaçla bilgisayar teknolojisinin kullanılmaya başlandığı ilk dönemlerden itibaren birçok çalışma yapılmıştır [2,3]. Günümüzde; güç sistemleri alanında pratik, teorik ve eğitim amaçlı kullanımlar için bilgisayar destekli programlara yönelik olan ihtiyacın her geçen gün arttığı bilinmektedir [4]. Güç sistemlerinin işletiminin gittikçe karmaşıklaşması, bu sektörde çalışan kişilerin eğitimi için yeni araçlar geliştirilmesini zorunlu hale getirmiştir. Bilgisayar destekli programlama ve tasarımın sağladığı birçok avantaj, geliştirilen güç sistemleri analiz programlarının sayısını arttırmıştır. Bu analiz programları endüstrinin talebine göre gelişim göstermiş ve ticarileşmişlerdir $[5,6]$. Fakat bir yandan da ticarileşmeye bağlı olarak eğitim odaklı kullanım için karmaşık ve pahalı hale gelmişlerdir. Dolayısıyla özellikle elektrik mühendisliği eğitimi gören öğrencilerin, güç sistemlerine olan ilgilerinin artması için güç sistemi analizi yapan bilgisayar araçlarının eğitimde daha çok kullanılması gerekmektedir [7,8]. Bilgisayar teknolojisindeki hızlı ilerleme sayesinde kişisel bilgisayarlarda kullanıma hazır hale getirilen ve grafik ortamının daha etkin kullanılmasına olanak tanıyan programlar, güç sistemlerini birçok yönden analiz edebilecek şekilde tasarlanmıştır [9-11]. Örneğin: Mathcad, Mathematica, Matpower, Neplan, Pscad, Etap, PowerWorld, Uwpflow, Gyte, VST, ATP/EMTP ve PSpice gibi araçlarla, güç sistemlerinin farklı işletme ve çalışma tiplerine göre analizleri yapılabilmektedir. Sonuçların görsel olarak sunulması veya ara işlemlerin gösterilmeden doğrudan sayısal sonuçların kullanıcıya aktarılması, söz konusu programların büyük çoğunluğunda karşılaşılan bir durumdur. Karmaşık yapıdaki güç sistemleri hakkında mühendislere, operatörlere ve teknik elemanlara ön bilgiler verilmesi, elde edilen bu sonuçlar vasıtasıyla mümkün olmaktadır. Güç sistemleri üzerinde gerçekleştirilecek işlemlerin kontrollü ve bilinçli bir şekilde yapılmasına,

\footnotetext{
${ }^{1}$ Sorumlu yazar: hcakar@firat.edu.tr Yazarların ORCID Numarası: 0000-0002-4918-9401, 20000000217741986
} 
kullanılan paket programlar imkân tanımaktadır [12-14]. Bilgisayar tabanlı eğitim aracı geliştirmekte kullanılan programlardan birisi de Matlab'dır. Matlab, teknik hesaplamalar ve matematiksel problemlerin çözümü ve analizi için tasarlanmış bir yazılımdır. Matlab özellikle üniversitelerin mühendislik bölümlerinin birçok lisans ve yüksek lisans dersinde yaygın olarak kullanılmaktadır. Çok çeşitli yüksek seviyeli matematiksel fonksiyonları, etkileyici ve kolay çizim özellikleri; bu programın göze çarpan özellikleri arasındadır. Bazı ticari olmayan güç sistemi yazılım paketleri; Matlab dili kullanılarak tasarlanabilmektedir [15,16]. Matlab ayrıca Guide (Graphical User Interface Development Environment) adı verilen araç kutusu ile bilgilerin görselleştirilmesine imkân sağlayan, kullanımı kolay grafik kullanıcı ara yüzleri (Gui) hazırlanmasına imkân tanımaktadır. GUI ara yüzüne; tıkla ve sürükle-bırak tekniği ile nesneler (örneğin butonlar, text kutuları, liste kutuları, grafikler vs.) kolaylıkla eklenebilir. Ayrıca, eklenen nesnelerin hizalanması, tab sırasının değiştirilmesi, görsel ayarlar üzerinde manipülasyonlar yapılması da bu ortamın tasarımcılara sunduğu imkânlardan bazılarıdır [17-20].

Bu çalışmada, elektrik güç sistemleri analizi ve tasarımlarında kullanılması için Matlab yazılımını kullanarak çalışan ve grafiksel kullanıcı ara yüzüne (GUI) sahip, GSAP adında yeni bir eğitsel yazılım paketi geliştirilmiştir. Güç sistemleri alanında kod yazmayı öğrenmek isteyen birisi bu programın içyapısını görebilmektedir, yani program açık kaynak kodludur. Araştırmacılar ve eğitimciler, çalışması kolay ve kod yapısı basit tutulan bu benzetim aracı sayesinde güç sistemleri analizi konusunda verimli ve etkili uygulamalar oluşturabilmektedir. GSAP; hata analizi, iletim hatları analizi, kesici açma gücü hesabı ve yük akışı analizi konularını içeren bir paket programdir.

\section{GSAP Paket Programı}

GSAP; eğitim alanında kullanılabilecek, matematiksel temele dayalı, elektrik güç sistemleri analiz ve çalışmaları için sağlanmış bir ortamdır. Program; Windows 10 işletim sistemi altında Matlab kullanılarak yazılmıştır. GSAP'ın performansı; Matlab programının sınırlamalarına ve kapasitesine bağlıdır. Bilindiği gibi Matlab; Macintosh, IBM vb. birçok platformu desteklemektedir, dolayısıyla geliştirilen bu yazılım herhangi bir değişiklik yapılmadan söz konusu platformlarda da çalıştırılabilmektedir. GSAP paket programını çalıştırmadan önce, mevcut dosya konumu uygun bir şekilde ayarlanmalıdır ve ana program menüsünün açılması için Matlab komut satırına "gsap" yazılmalıdır (Şekil 1).

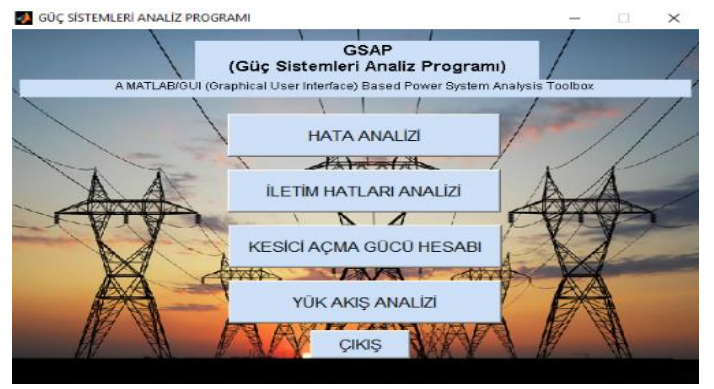

Şekil 1. GSAP ana programının kullanıcı ara yüzü

\section{GSAP Uygulamaları}

Bu bölümde, GSAP programının etkinliğini ve geçerliliğini göstermek için, her bir modül için ayrı ayrı örnek uygulamalar gerçekleştirilmiştir.

\subsection{Hata analizi için örnek uygulama}

Şekil 2' de tek hat diyagramı verilen güç sistemi için per unit olarak bara empedans matrisi (Denklem 1) aşağıdaki gibidir.

$$
Z_{\text {bus }}=j\left[\begin{array}{cccc}
0.150 & 0.075 & 0.140 & 0.135 \\
0.075 & 0.1875 & 0.090 & 0.0975 \\
0.140 & 0.090 & 0.2533 & 0.210 \\
0.135 & 0.0975 & 0.210 & 0.2475
\end{array}\right]
$$


4 nolu barada üç fazlı kısa devre oluşmuş ve hata empedansı $Z_{f}=j 0.0025$ (p.u.) 'dir. Bara empedans matrisi kullanılarak hata akımı, bara gerilimleri ve hata boyunca hat akımları, hata analizi programı çalıştırılarak bulunmuştur.

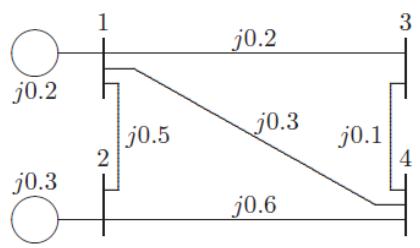

Şekil 2. Örnek güç sisteminin tek hat diyagramı

Yapılan hesaplamalar neticesinde verilen güç sistemi ağı için hat verisi aşağıdaki gibi oluşmaktadır.

$Z_{\text {data }}=\left[\begin{array}{llll}0 & 1 & 0 & 0.2 \\ 0 & 2 & 0 & 0.3 \\ 1 & 2 & 0 & 0.5 \\ 1 & 3 & 0 & 0.2 \\ 1 & 4 & 0 & 0.3 \\ 2 & 4 & 0 & 0.6 \\ 3 & 4 & 0 & 0.1\end{array}\right]$

Öncelikle Denklem 2'deki matrisin elemanları yani hat verisi programa girilmelidir. Matriste 7 satır olduğu için, programda bulunan "Hücre Ekle" düğmesine tıklayarak, 7 tane hücre oluşturulur. İstenirse "Hücre Sil" düğmesine tıklanarak, yanlış eklenen hücreler silinebilmektedir. "Veri Sil” düğmesi, o bölümdeki tüm hücreleri silebilmektedir. Empedans sütununa değerler girilirken, imajiner olarak girilmelidir. Örneğin 1. satırdaki empedans değeri $0.2 \mathrm{i}$ olarak girilmelidir. Empedans matrisinin elemanları sirasıyla girildikten sonra " $Z-Y$ Dönüştür” düğmesi ile admitans matrisine dönüşüm sağlanmaktadır (Şekil 3). Bir sonraki aşamada programın sağ üst tarafinda bulunan hatalı bara, hata empedansı, Baz MVA ve kVA oranı değerleri girilmeli, ardından hata tipi belirtilmelidir. Örnekte üç fazlı hata oluştuğu için programda hata tipi üç faz olarak seçilmiştir (Şekil 4).

\begin{tabular}{|l|r|r|r|r|}
\hline & Baradan & Baraya & Empedans & \multicolumn{1}{c|}{ Admitans } \\
\hline 1 & 0 & 1 & $0.0000+0.2000 \mathrm{i}$ & $0.0000-5.0000 \mathrm{i}$ \\
\hline 2 & 0 & 2 & $0.0000+0.3000 \mathrm{i}$ & $0.0000-3.3333 \mathrm{i}$ \\
\hline 3 & 1 & 2 & $0.0000+0.5000 \mathrm{i}$ & $0.0000-2.0000 \mathrm{i}$ \\
\hline 4 & 1 & 3 & $0.0000+0.2000 \mathrm{i}$ & $0.0000-5.0000 \mathrm{i}$ \\
\hline 5 & 1 & 4 & $0.0000+0.3000 \mathrm{i}$ & $0.0000-3.3333 \mathrm{i}$ \\
\hline 6 & 2 & 4 & $0.0000+0.6000 \mathrm{i}$ & $0.0000-1.6667 \mathrm{i}$ \\
\hline 7 & 3 & 4 & $0.0000+0.1000 \mathrm{i}$ & $0.0000-10.0000 \mathrm{i}$ \\
\hline
\end{tabular}

Şekil 3. Bara empedans matrisinin programa girilmesi ve admitans dönüşümü

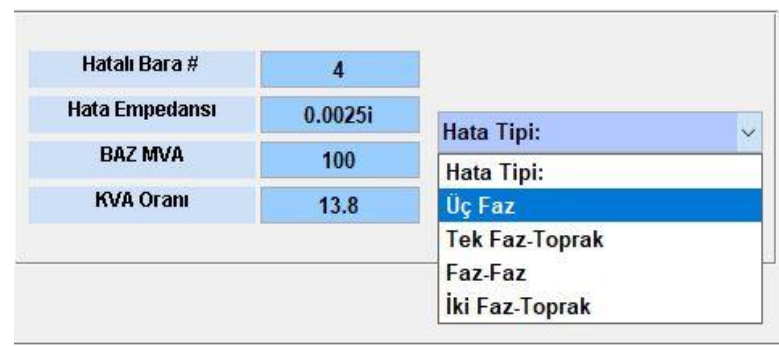

Şekil 4. Hatalı bara, hata empedansı, baz MVA, KVA oranı ve hata tipinin seçilmesi

Örnekte üç faz hata söz konusu olduğu için sadece "Pozitif Bileşen” düğmesine basılarak, pozitif bileşen dizisinin empedans ve admittans değerleri görüntülenmiştir (Şekil 5). 


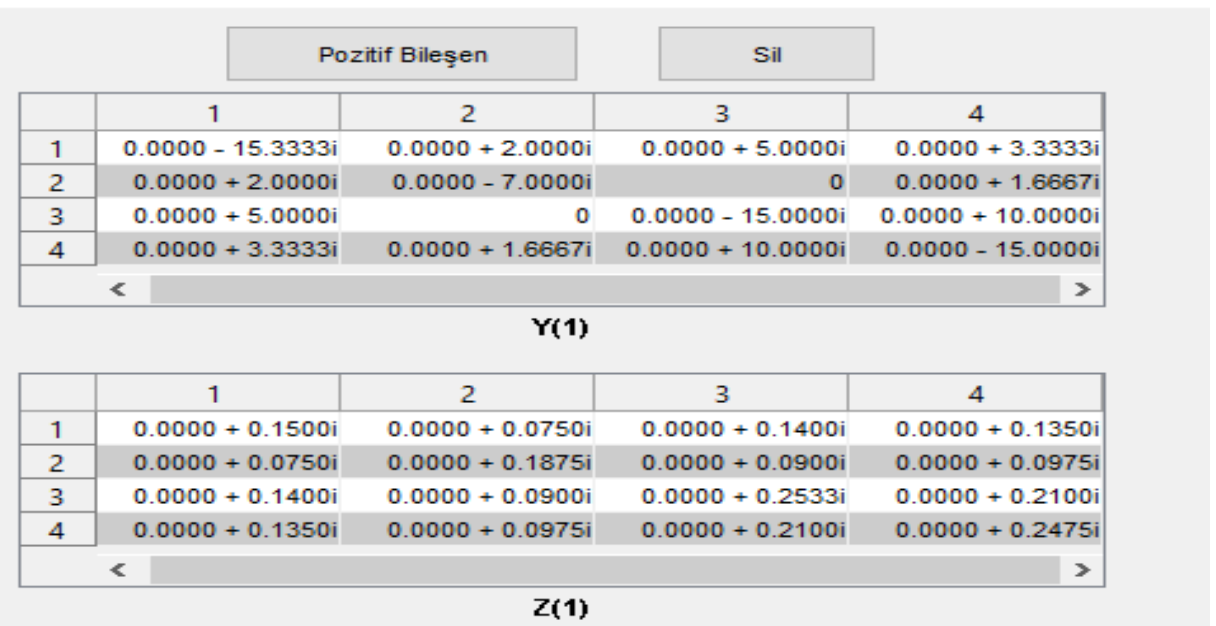

Şekil 5. Pozitif dizi bileşeninin elde edilmesi

"HESAPLA" düğmesine basıldıktan sonra bara gerilimlerinin büyüklük ve açı değerleri Şekil 6' da; baradan baraya hat akımlarının büyüklük ve açıları ile hata akımlarının p.u. ve A cinsinden değerleri Şekil 7' de verilmiştir.

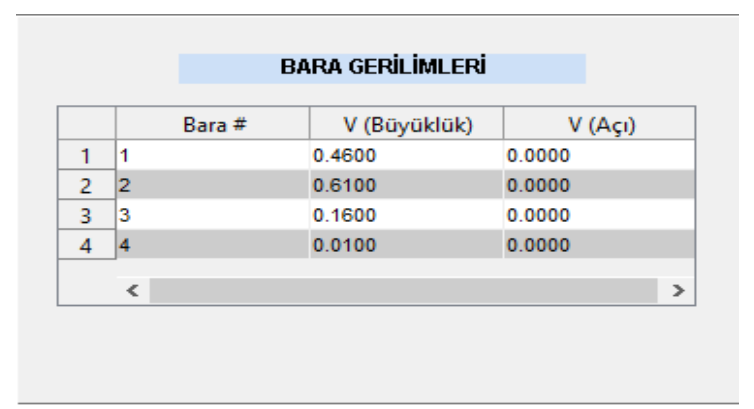

Şekil 6. (4) nolu baradaki hata durumu için bara gerilimlerinin elde edilmesi

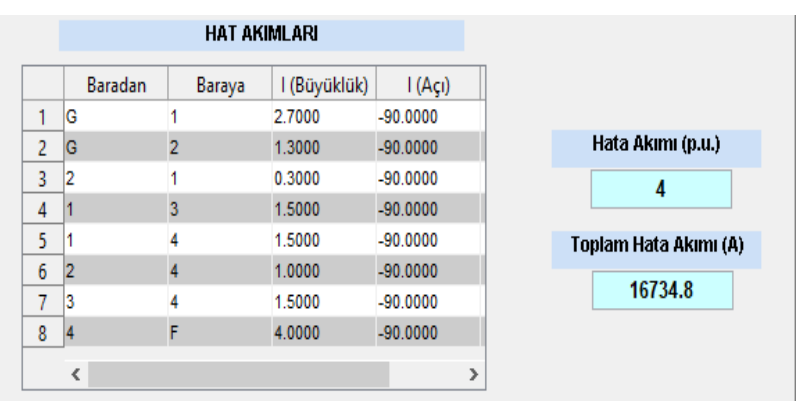

Şekil 7. (4) nolu baradaki hata durumu için hat akımlarının ve hata akımı değerinin elde edilmesi

\section{2. İletim hatları analizi için örnek uygulama}

Şekil 8'deki devrede; hat sonu akımı, hat başı akımı, hattın verimi, hat sonu gerilimi, hat başı güç faktörü, hat başı aktif gücü, hattaki aktif güç kaybı ve gerilim regülasyonu iletim hatları analiz modülü kullanılarak hesaplanmıştır. Giriş verileri bölümüne değerler girilip, "Klsa Illetim Hattı" düğmesine basıldıktan sonra elde edilen grafik ve çıkış verileri Şekil 9' da verilmiştir.

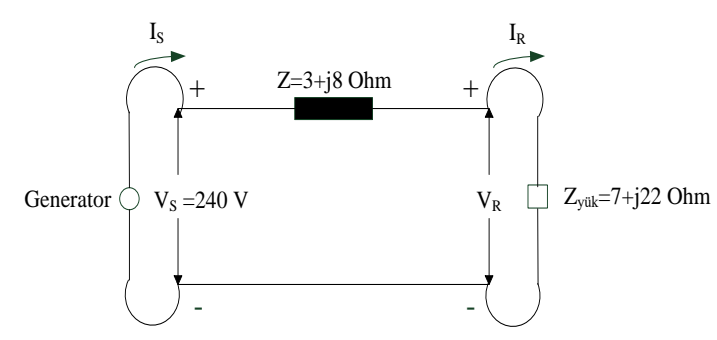

Şekil 8. İletim hatları analizi için örnek hat modeli 


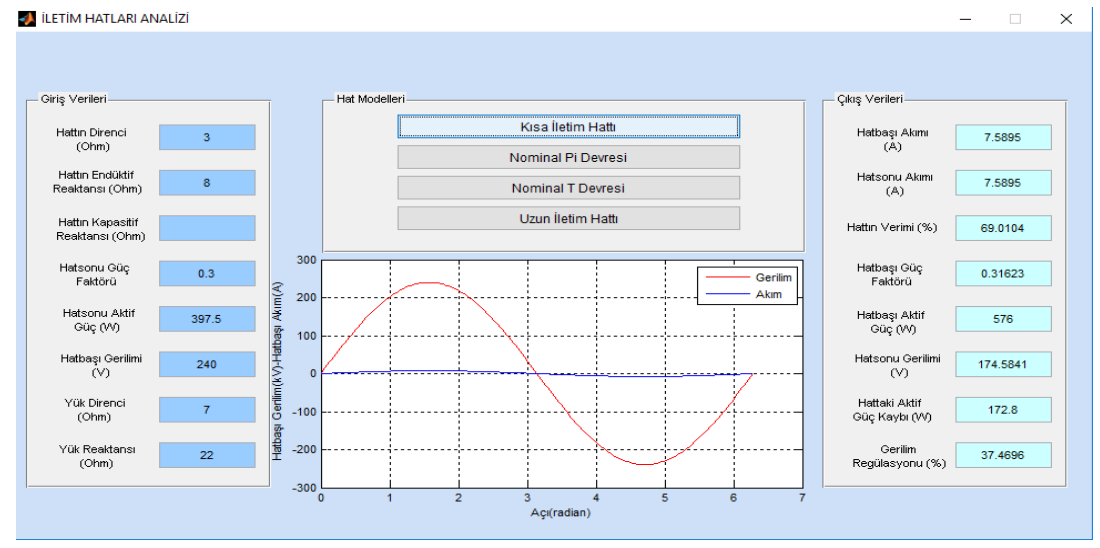

Şekil 9. Kısa iletim hattı için elde edilen grafik ve çıkış verileri

Giriş verileri bölümüne değerler girilip, "Nominal П Devresi” düğmesine basıldıktan sonra elde edilen grafik ve çıkış verileri Şekil 10'da; "Nominal T Devresi" düğmesine basıldıktan sonra elde edilen grafik ve çıkış verileri ise Şekil 11' de verilmiştir. Nominal $\prod$, nominal T ve uzun iletim hatları için hattın kapasitif reaktans değeri keyfi olarak $100 \mathrm{ohm}$ seçilmiştir.

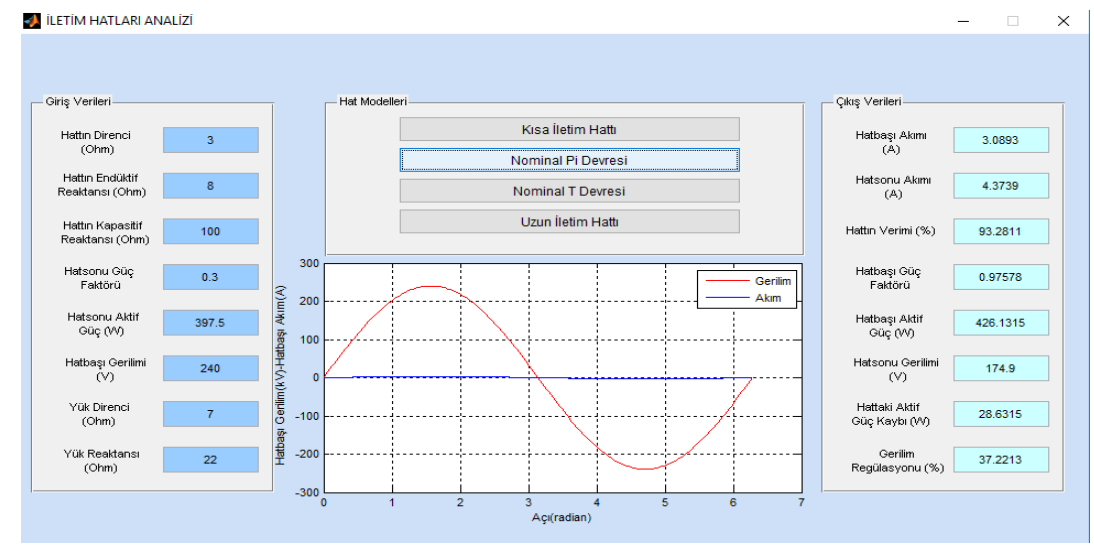

Şekil 10. Nominal pi devresi için elde edilen grafik ve çıkış verileri

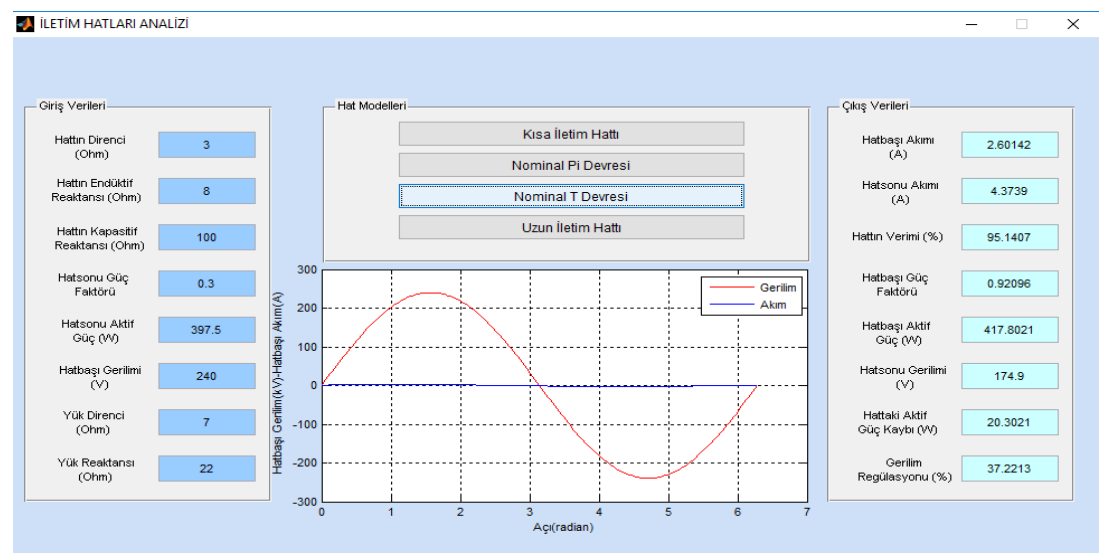

Şekil 11. Nominal T devresi için elde edilen grafik ve çıkış verileri

Giriş verileri bölümüne değerler girilip, "Uzun Illetim Hattı" düğmesine basıldıktan sonra elde edilen grafik ve çıkış verileri Şekil 12'de verilmiştir. 


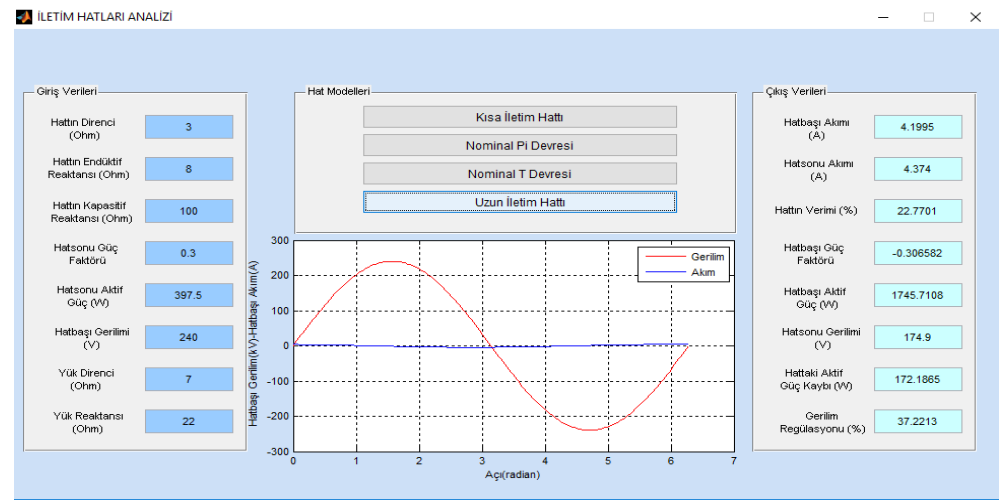

Şekil 12. Uzun iletim hattı için elde edilen grafik ve çıkış verileri

Nominal $\mathrm{T}$ ve Nominal $\prod$ devresi tamamen gerçek hattı göstermemektedir. Hat uzunluğunun şüpheli durumlarında hesaplarda tam doğruluk elde etmek için, gerçek hattı gösteren eşdeğer T ve eşdeğer $\prod$ devrelerinin kullanılması en iyi yoldur. Nominal $\prod$ ve nominal $\mathrm{T}$ devrelerinden elde edilen sonuçlar her ne kadar birbirine çok yakın görünse de tamamen aynı olmaları mümkün değildir.

\subsection{Kesici açma gücü hesabı için örnek uygulama}

Şekil 13'deki sistemde D noktasındaki üç fazlı kısa devrede, kısa devre akımlarının ve güçlerinin bulunması istenmektedir.

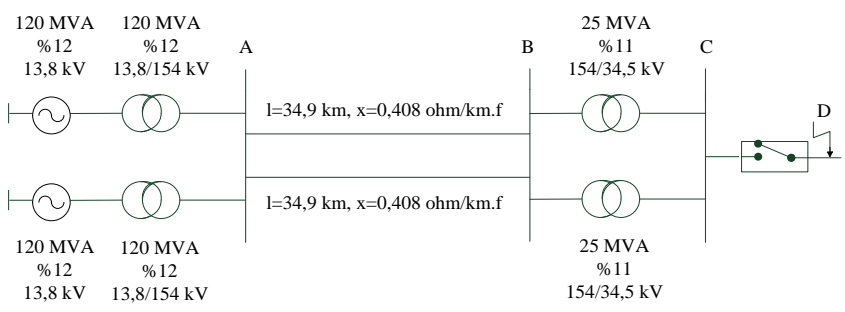

Şekil 13. Kesici açma gücü hesabı için örnek bir güç sistemi

Şekil 13'de verilen örnek güç sistemindeki değerler uygun bir şekilde kesici açma gücü hesabı modülünde girilip, hesapla düğmesine basıldığında, program hassas ve doğru bir şekilde gerekli hesaplamaları yaparak, çıkış verileri olarak istenen sonuçları kullanıcının karșısına çıkarmaktadır. Başlangıç kısa devre alternatif akımının, kısa devreyi besleyen generatörlerin toplam gücüne karşıllk olan ve kısa devre yerindeki anma gerilimine göre hesaplanan anma akımına oranı 2 değerinden küçük olduğu için, "generatöre uzak bir kısa devre" şeklinde bir uyarı mesajı alınmıştır (Şekil 14'de gösterildiği gibi).

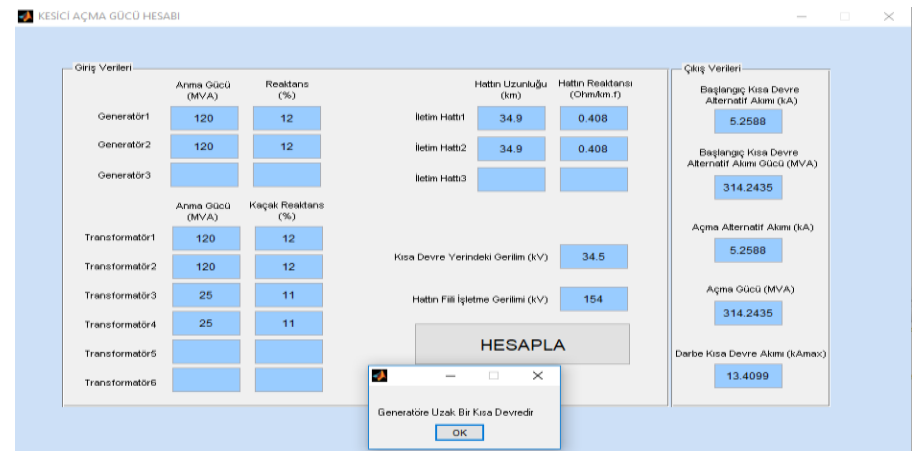

Şekil 14. Kesici açma gücü hesabı modülünün elde ettiği çıkış verileri 


\subsection{Yük akışı analizi için örnek uygulama}

Aşağıda tek hat şeması verilen 30 baralı test sistemi için sırasıyla Newton-Raphson, Gauss Seidel ve Fast Decoupled yöntemleri yük akış analiz programında uygulanarak yük akış çözümleri elde edilmiştir.

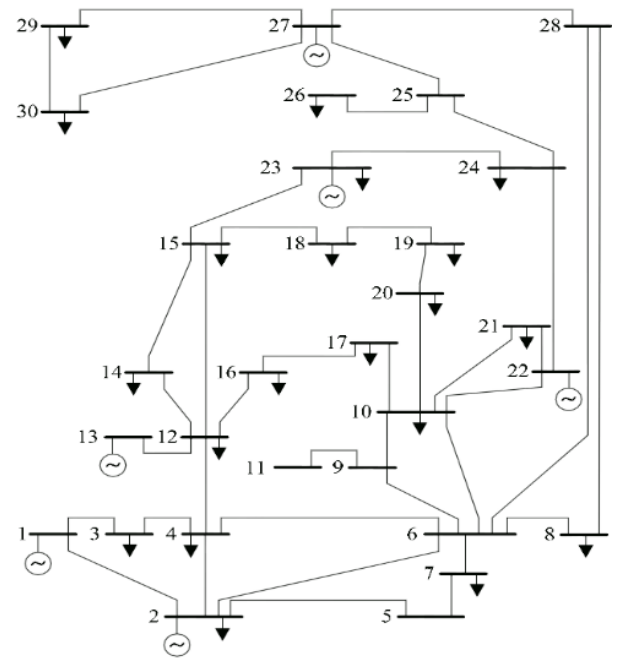

Şekil 15. IEEE 30 baralı test sisteminin tek hat şeması

\subsubsection{Newton-Raphson yöntemi}

Giriş bilgileri bölümünde; Baz Güç = 100 MVA; Tolerans Değeri = 0.001; Hızlandırma Faktörü = 1.8; Maksimum İterasyon Sayısı = 100 olarak girilmiştir (Şekil 16). Bara numaralarına karşılık, gerilim (p.u) ve faz açı (derece) değerlerini gösteren grafik Şekil 17' de verilmiştir.

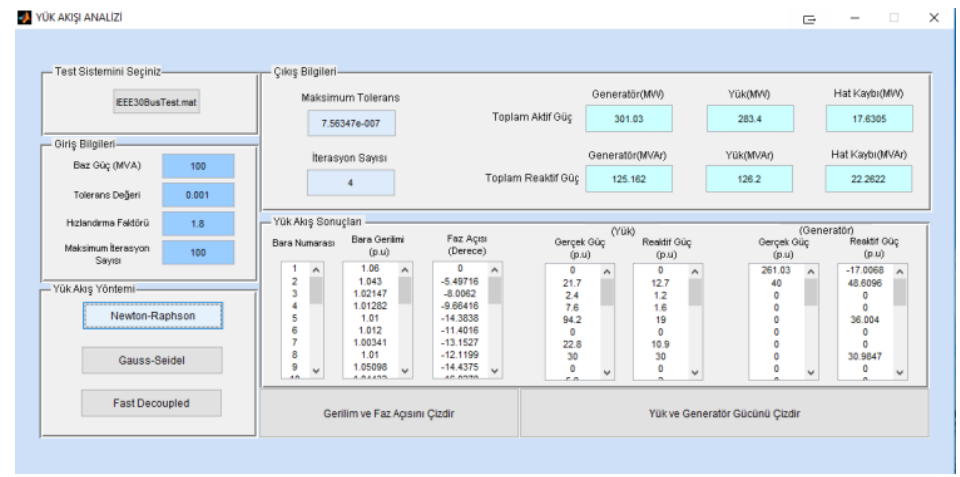

Şekil 16. Yük akış analizi programında Newton-Raphson yönteminin çalıştırılması

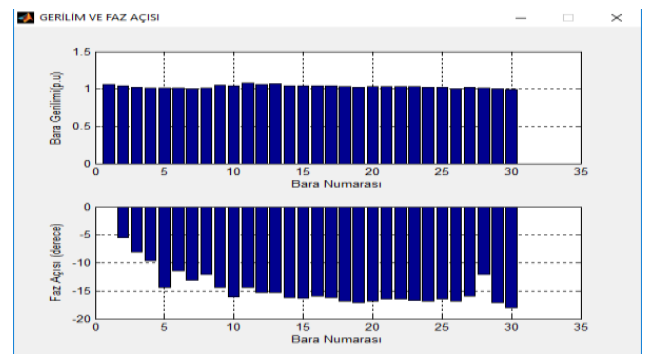

Şekil 17. Newton-Raphson yöntemi için bara gerilim ve faz açısının grafiksel çizimi 
Bara numaralarına karşılık, yükün talep ettiği aktif ve reaktif güç değerlerini (p.u) ve generatör tarafindan üretilen aktif ve reaktif güç (p.u) değerlerini gösteren grafik Şekil 18’ de verilmiştir.

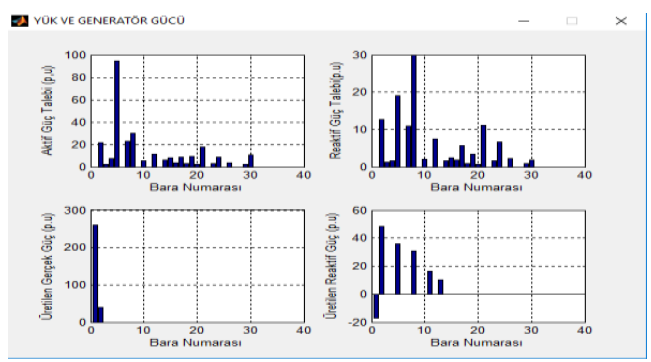

Şekil 18. Newton-Raphson yöntemi için yük ve generator güçlerinin grafiksel çizimi

\subsubsection{Gauss-Seidel yöntemi}

Yük akış analizi programında Gauss-Seidel yönteminin çalıştırılması aşağıda verilmiştir (Şekil 19). Bara numaralarına göre, gerilim (p.u) ve faz açısı (derece) değerleri Şekil 20’ de gösterilmiştir.

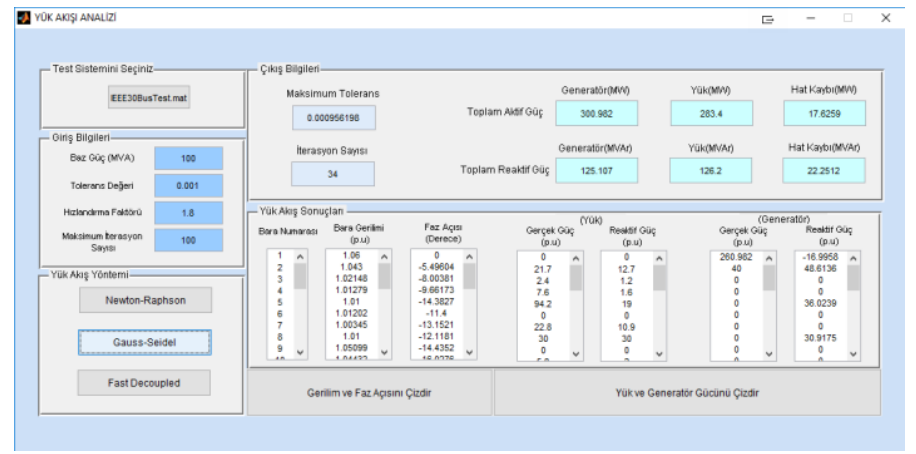

Şekil 19. Yük akış analizi programında Gauss-Seidel yönteminin çalıştırılması

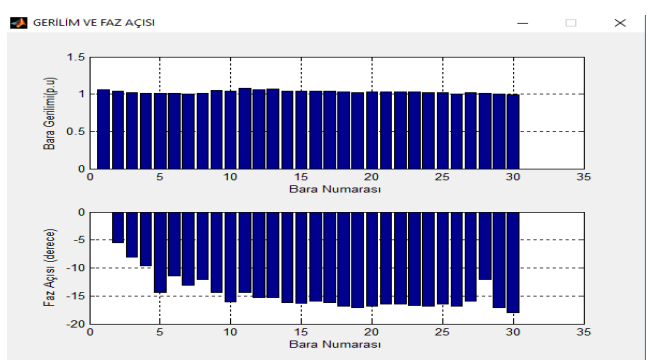

Şekil 20. Gauss-Seidel yöntemi için bara gerilim ve faz açısının grafiksel çizimi

Bara numaralarına göre, yükün talep ettiği aktif ve reaktif güç değerleri (p.u) ve generatör tarafından üretilen aktif ve reaktif güç (p.u) değerleri Şekil 21' de verilmiştir.

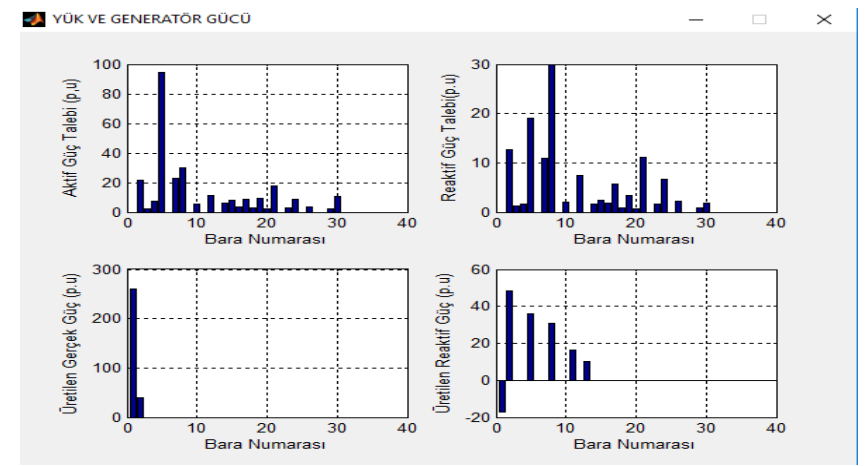

Şekil 21. Gauss-Seidel yöntemi için yük ve generator güçlerinin grafiksel çizimi

\subsubsection{Fast-Decoupled yöntemi}

Yük akış analizi programında Fast-Decoupled yönteminin çalıştırılması aşağıda verilmiştir (Şekil 22). 


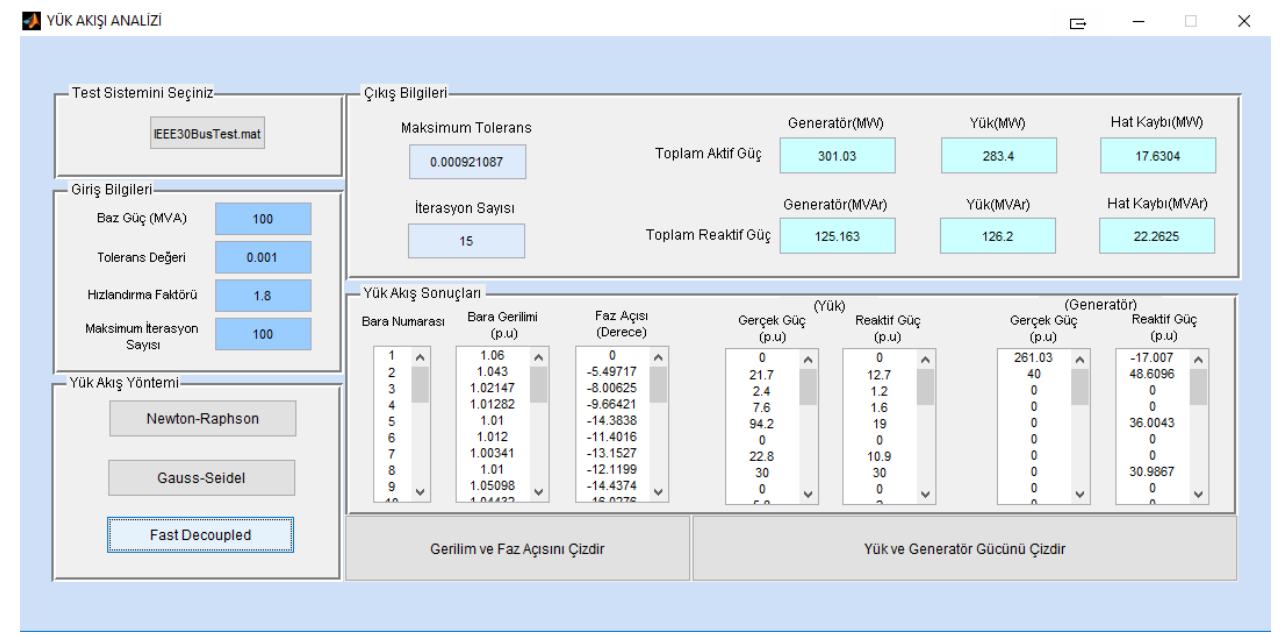

Şekil 22. Yük akış analizi programında Fast-Decoupled yönteminin çalıştırılması

Bara numaralarına karşılık, gerilim (p.u) ve faz açısı (derece) değerleri Şekil 23' de verilmiştir.

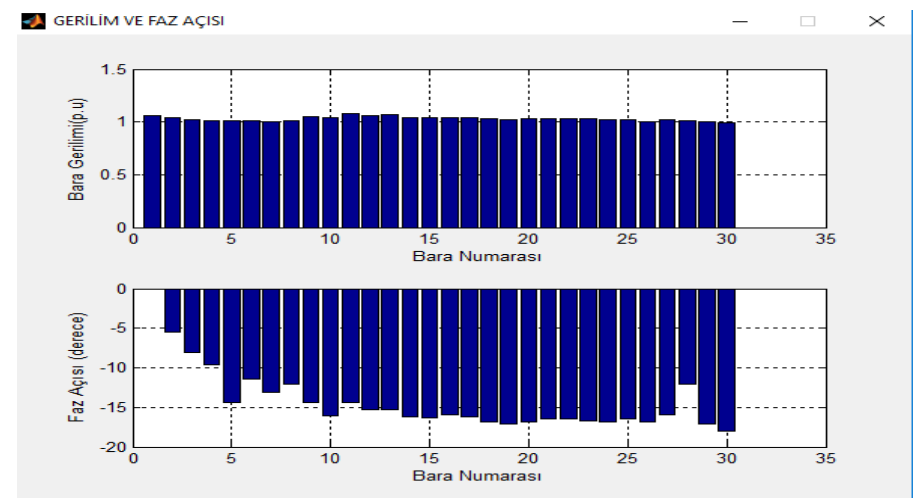

Şekil 23. Fast-Decoupled yöntemi için bara gerilim ve faz açısının grafiksel çizimi

Bara numaralarına göre, yükün talep ettiği aktif ve reaktif güç değerleri (p.u) ve generatör tarafından üretilen aktif ve reaktif güç (p.u) değerleri Şekil 24'de verilmiştir.

Y YüK VE GenERATÖR GÜCü
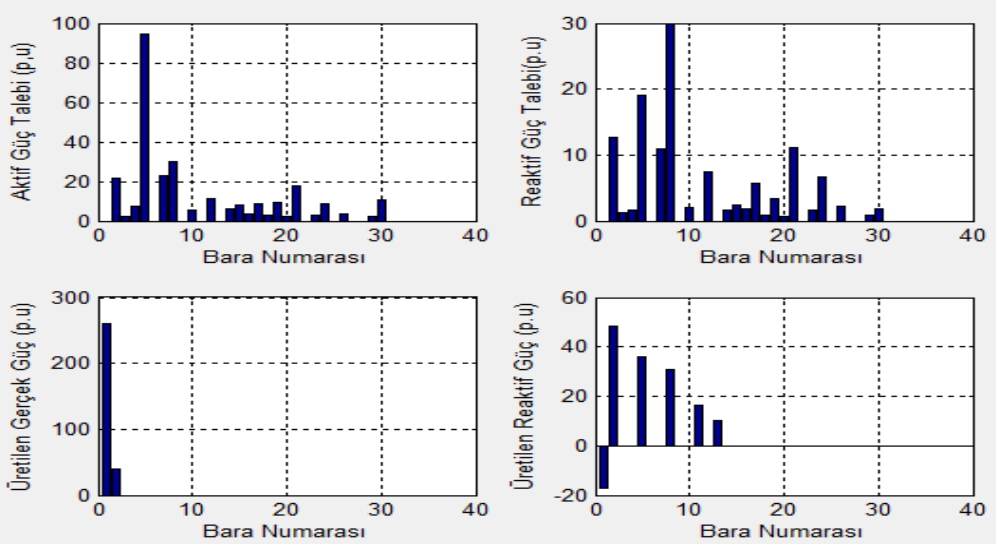

Şekil 24. Fast-Decoupled yöntemi için yük ve generator güçlerinin grafiksel çizimi 


\section{Sonuçlar}

$\mathrm{Bu}$ çalışmada; Matlab'da geliştirilen bir yazılım paketi güç sistem analizi ve eğitimi için sunulmuştur. Geliştirilen program, dört uygulama modülü içermektedir. İstenilen analizlerin GUI alt programlarındaki menüler yardımıyla kolaylıkla yapılabilmesi için, sadece üzerinde çalışılacak sistemin verilerinin girilmesi yeterlidir. GSAP programındaki alt programların çalışma performansları, etkinlik ve geçerlilikleri bazı örnek güç sistem uygulamaları ele alınarak incelenmiş ve bu programın öğretici bir araştırma aracı olduğu analiz sonuçlarından görülmüştür. Matlab grafik kullanıcı arabirimi sayesinde güç sistem eleman parametrelerinin gereksiz ve hatalı girilmesi önlenmiştir. Program, kullanılabilirlik açısından en basit hale indirgenmeye çalışılmış ve kodlama aşamasında mümkün olduğunca sade bir kod yapısı tercih edilerek, ilerisi için geliştirmeye açık bırakılmıştır. Güç sistemlerinde kod yazmayı merak eden birisi programın içyapısını rahatlıkla görebilmektedir. Çünkü GSAP paket yazılımı açık kaynak kodludur. Üniversitelerde lisans ve yüksek lisans düzeyindeki güç sistem derslerini gören öğrenciler GSAP ile ödev hazırlayabilir veya isterlerse Matlab araç kutularını kullanarak yeni alt programlar yazabilirler. Sonraki çalışmalarda kullanıcıların grafik kullanıcı arabirimden beklentileri doğrultusunda programa daha fazla modül eklenerek işlevselliği arttırabilir ve internet temelli uzaktan güç sistem eğitiminde yer alması sağlanabilir.

\section{Kaynaklar}

[1] Overbye Thomas J, et al. A user-friendly simulation program for teaching power system operations. IEEE Transactions on Power Systems 1995;10(4) : 1725-1733.

[2] Ortmeyer Thomas H. Applications of microcomputers in power system protection education. IEEE transactions on power systems 1998; 3(4): 1847-1850.

[3] Tamura Y, et al. Development of power system simulator for research and education. IEEE Transactions on Power Systems 1990; 5(2): 492-498.

[4] Berry Frederick C, Philip S. DiPiazza, Susan L. Sauer. The future of electrical and computer engineering education. IEEE Transactions on Education 2003;46(4): 467-476.

[5] Chu K K, H W Ngan. A Novel Approach for Implementing Power System Analysis and Simulation Tools. International journal of engineering education 2001; 17(3): 312-320.

[6] Neyer Andreas, Felix F Wu, Karl Imhof. Object-oriented programming for flexible software: Example of a load flow. IEEE Transactions on Power Systems 1990; 5(3): 689-696.

[7] Abur Ali, Fernando Magnago, Yunqiang Lu. Educational toolbox for power system analysis. IEEE Computer Applications in Power 2000;13(4): 31-35.

[8] Ngundam J M, ER Ngalemo Ngalemo, F Kenfack. Virtual lab for power system simulation. I. Interactive design of power networks and load flow analysis. Power engineering journal 2001; 15(4): 211-215.

[9] Levi Viktor A, Dusko P. Nedic. Application of the optimal power flow model in power system education. IEEE Transactions on power systems $2001 ; 16(4)$ : $572-580$

[10] Islam S, Nurul Chowdhury. A case-based windows graphic package for the education and training of power system restoration. IEEE Transactions on Power Systems 2001; 16(2): 181-187.

[11] Shin Joong-Rin, Wook-Hwa Lee, Dong-Hae I. A windows-based interactive and graphic package for the education and training of power system analysis and operation. IEEE Transactions on Power Systems 1999; 14(4): 1193-1199.

[12] Allen Eric, et al. Interactive object-oriented simulation of interconnected power systems using SIMULINK. IEEE Transactions on Education 2001; 44(1): 87-94.

[13] Gözel T, Hocaoğlu M H. Güç Sistem Analizi İçin Grafik Kullanıcı Arabirimi, Eleco'2004 Elektrik-Elektronik-Bilgisayar Mühendisliği Sempozyumu; 2004. Bursa, s:301-305.

[14] Ayasun Saffet, et al. Symbolic analysis and simulation for power system dynamic performance assessment. Power Engineering Society General Meeting; 2005.

[15] Ekinci S, Demiroren A, Zeynelgil H L. PowSysGUI: A new educational software package for power system stability studies using MATLAB/Simulink. International Journal of Electrical Engineering Education 2017;54(4): 283-298.

[16] Cole Stijn, Ronnie Belmans M. A new matlab-based toolbox for power system dynamic simulation. IEEE Transactions on Power systems 2011; 26(3): 1129-1136.

[17] Yu David C, et al. A graphical user interface for design, simulation and analysis of power plant electrical auxiliary systems. IEEE transactions on energy conversion 1994; 9(2): 263-269.

[18] Foley Mike, et al. An object based graphical user interface for power systems. IEEE Transactions on Power Systems 1993; 8(1): 97-104.

[19] Yu David C, Dennis G. Flinn, Robert A Krieger. Facilitating engineering analysis via a graphical database. IEEE transactions on power systems 1995; 10(1): 370-375.

[20] Yu D C, et al. A windows based graphical package for symmetrical components analysis. IEEE Transactions on Power Systems 1995; 10(4): 1742-1749. 